\title{
Antibodies to Chlamydia trachomatis, Mycoplasma hominis, and Neisseria gonorrhoeae in sera from patients with acute salpingitis
}

\author{
PER-ANDERS MÅRDH,* INGA LIND,† LARS SVENSSON, \\ AND BIRGER R M $\varnothing$ LLER $\S$ \\ From the *Institute of Medical Microbiology, University of Lund, Sweden; the †Neisseria Department, \\ Statens Seruminstitut, Copenhagen, Denmark; the ₹Department of Gynaecology and Obstetrics, \\ University Hospital, Lund, Sweden; and the §Institute of Medical Microbiology, University of Aarhus, \\ Denmark
}

SUMMARY Paired sera from 60 consecutive patients with acute salpingitis, confirmed by laparoscopy, were examined for serum antibodies to Chlamydia trachomatis, Mycoplasma hominis, and Neisseria gonorrhoeae. By a microimmunofluorescence (MIF) test IgM or IgG antibodies to $C$ trachomatis or both were present in sera from $80 \%$ of the patients; by indirect haemagglutination (IHA) tests antibodies to $M$ hominis and $N$ gonorrhoeae pilar antigens were present in $40 \%$ and $18 \%$ respectively. In a control group of 50 pregnant women antibodies to the same three organisms occurred in $8 \%, 8 \%$, and $6 \%$. Evidence of current chlamydial infection was found in $35(58 \%)$ and of current gonococcal infection in five $(8 \%)$ of the 60 patients by culture or serological tests or both. The results of chlamydial antibody tests correlated with the severity of the tubal inflammation (as shown by laparoscopy) and the duration of the lower abdominal pain before attendance. The predictive values of a positive and a negative MIF test result were $44 \%$ and $83 \%$ respectively and of the IHA gonococcal antibody test $36 \%$ and $100 \%$ respectively. Significant rises in titre of antibodies to $M$ hominis were found in $12 \%$ of patients. A four-fold or greater rise in titre indicated probable double infections with chlamydia and mycoplasmas in $\mathbf{7 \%}$ of patients. Thus, at present gonococcal salpingitis appears to form only a small proportion of all cases of salpingitis in southern Sweden, and in patients with nongonococcal salpingitis infections with $C$ trachomatis and $M$ hominis commonly occur.

\section{Introduction}

Although there are diverse opinions ${ }^{12}$ on the proportion of acute salpingitis that is caused by Neisseria gonorrhoeae, most workers agree that other agents can also be responsible for this condition. Nongonococcal salpingitis may be caused by a variety of organisms, the relative importance of which, however, seems to vary in different regions.

Some workers ${ }^{1-5}$ have proposed that gonococcal infections account for the vast majority of tubal infections. Others have presented evidence that nongonococcal salpingitis is at least as common as

Address for reprints: Dr P-A Mårdh, Institute of Medical Microbiology, University of Lund, Solvegatan 23, S-223 62 Lund, Sweden

Accepted for publication 7 October 1980 gonococcal salpingitis in their hospital catchment areas $^{26-9}$ and that the proportion of nongonococcal cases has increased during the last decade. ${ }^{710}$

We have shown that Chlamydia trachomatis ${ }^{71-13}$ and Mycoplasma hominis ${ }^{814} 15$ are agents that may cause nongonococcal pelvic inflammatory disease (PID). In the present study, we tested paired sera from consecutive patients with acute salpingitis for antibodies to $C$ trachomatis by an indirect immunofluorescence test and for antibodies to $M$ hominis and $N$ gonorrhoeae by indirect haemagglutination tests.

\section{Patients and methods}

STUDY POPULATION

The series of patients with salpingitis were 60 consecutive cases treated at the department of 
obstetrics and gynaecology at the University Hospital, Lund, Sweden, and were verified by laparoscopy ${ }^{16} ; 19$ cases were classified as severe, 25 as moderately severe, and 16 as mild. Paired sera were obtained; the time elapsing between the collection of the two specimens varied from four to 60 days (mean $15 \cdot 7$ days). The ages of the patients varied from 14 to 48 years (mean 23.5 years). Ten of the patients had had one previous episode of salpingitis and one had had more than one.

\section{CONTROLS}

Sera from 50 pregnant women attending consecutively from the same hospital catchment area served as controls. Their ages ranged from 17 to 38 years (mean 23.8 years). Whether any of these women had previously had salpingitis was not known.

\section{SEROLOGY}

A modified microimmunofluorescence (MIF) test ${ }^{17}$ using three pools of antigen of $C$ trachomatis-immunotypes A-C, D-K. (except J), and LGV 1-3-was used to demonstrate both IgM and IgG antibodies.

Antibodies to $M$ hominis were detected by an indirect haemagglutination test, which was in principle performed as described by KrogsgaardJensen. ${ }^{18}$ The antigen was prepared from strain D188 of $M$ hominis, which had been isolated from the cervix of a patient with acute salpingitis. After centrifugation of sonically treated cells, the supernatant fluid was used to sensitise formalised sheep erythrocytes.

Gonococcal antibodies were determined by an indirect haemagglutination (IHA) test, using pilar antigens prepared from two strains of $N$ gonorrhoeae. ${ }^{19}$

In the microimmunofluorescence tests, titres of $\geqslant 16$ (IgM) and $\geqslant 32$ (IgG) were considered to give positive results for antibodies to $C$ trachomatis, while titres $\geqslant 40$ were considered to give positive results in both indirect haemagglutination tests.

\section{CULTURE}

The techniques used for the isolation and identification of $C$ trachomatis and $N$ gonorrhoeae were those described. ${ }^{11}$ Cervical specimens were cultured for $C$ trachomatis and cervical, urethral, and rectal specimens for $N$ gonorrhoeae. Cultures for $M$ hominis were not regularly performed and no cultures were performed for the control group.

\section{PREDICTIVE VALUES AND STATISTICAL CALCULATION}

The predictive values (for the diagnosis of chlamydial and gonococcal infection) for positive and negative test results by the MIF test (IgG) and by the IHA test for gonococcal pilar antibodies were calculated as described. ${ }^{20}$ Kendall's Tau-C test* was used to determine the correlation between the severity of the tubal inflammatory changes, the duration of pelvic pain before attendance, and the MIF titre to $C$ trachomatis on admission. In these determinations patients who seroconverted or had at least a fourfold rise in titre of IgM or IgG antibodies or both or had an IgM titre of $\geqslant 32$ or IgG titre of $\geqslant 512$ or both were considered to have a current chlamydial infection.

\section{Results}

\section{ANTIBODY TITRES}

The maximum titres for each patient of IgM and IgG antibodies to $C$ trachomatis and of antibodies to $M$ hominis and $N$ gonorrhoeae are shown in tables I and II. Antibodies (IgG or IgM or both) to $C$ trachomatis were detected in $80 \%$ of the patients and antibodies to $M$ hominis and $N$ gonorrhoeae in $40 \%$ and $18 \%$ respectively. IgM antibodies to $C$ trachomatis occurred in 12 and IgG antibodies in all 48 seropositive patients. A significant change in antibody titre to $C$ trachomatis occurred in $40 \%$ of the patients (21 with IgG, one with IgM, and two with both antibodies), to $M$ hominis in $12 \%$, and to $N$ gonorrhoeae in $5 \%$ (table III).

The predictive values for a positive and a negative MIF test result were $44 \%$ and $83 \%$ respectively; those for the IHA gonococcal pilar antibody test were $36 \%$ and $100 \%$ respectively. These calculations were based on the assumption that the diagnosis of a current infection was equivalent to a positive culture result for the organism.

\section{CULTURE AND SEROLOGY}

The results of cultural and serological studies are compared in table IV. None of the 12 patients with IgM antibodies to $C$ trachomatis was culture-positive for chlamydia. Evidence of a current infection (culture-positive or significant change of antibody titre or both) with $C$ trachomatis and $N$ gonorrhoeae occurred in $35(58 \%)$ and five $(8 \%)$ respectively. Of the 23 patients with positive cultures for chlamydia 17 , five, and one had titres of $<64,128-256$, and $>512$ respectively. Ten had a significant rise in the titre of antichlamdyial IgG antibodies.

The four patients who harboured gonococci were all in the group of 11 patients who had IHA pilar antibodies to $N$ gonorrhoeae. Two of the three patients with a significant rise in titre harboured gonococci.

* In these calculations the diagnosis of chlamydial and gonococcal infection was based on the result of cultures from the lower genital tract. 
TABLE I Maximum MIF test titres of IgM and IgG antibodies to Chlamydia trachomatis in 60 patients with acute salpingitis

\begin{tabular}{llllllllllllll}
\hline \multicolumn{11}{c}{ No of patients with titre: } \\
\cline { 2 - 11 } Ig class & $<8$ & 16 & 32 & 64 & 128 & 256 & 512 & 1024 & 2048 & 4096 & 8192 \\
\hline $\mathrm{M}$ & 48 & 2 & 2 & 1 & 5 & 1 & 1 & 0 & 0 & 0 & 0 \\
$\mathrm{G}$ & 11 & 1 & 5 & 14 & 7 & 4 & 8 & 2 & 4 & 3 & 1 \\
\hline
\end{tabular}

TABLE II Maximum titres of antibodies to Mycoplasma hominis and Neisseria gonorrhoeae in 60 patients with acute salpingitis

\begin{tabular}{llllll}
\hline & \multicolumn{6}{c}{ No of patients } & with & maximum antibody & titre: \\
\cline { 2 - 6 } Organism & $\leqslant 20$ & 40 & 80 & 160 & 320 \\
\hline$M$ hominis & 36 & 9 & 9 & 4 & 2 \\
$N$ gonorrhoeae & 49 & 3 & 4 & 2 & 2 \\
\hline
\end{tabular}

TABLE III Number and percentage of 60 patients with salpingitis showing antibodies to Chlamydia trachomatis, ${ }^{*}$ Mycoplasma hominis, and Neisseria gonorrhoeae

\begin{tabular}{lccc}
\hline & \multicolumn{4}{c}{ No (\%) of patients with antibody titre: } \\
\cline { 2 - 4 } Organism & Static & Increased $†$ & Total \\
\hline Chlamydia trachomatis & $26(43)$ & $22(37)$ & $48(80)$ \\
Mycoplasma hominis & $17(28)$ & $7(12)$ & $24(40)$ \\
Neisseria gonorrhoeae & $8(13)$ & $3(5)$ & $11(18)$ \\
\hline
\end{tabular}

* IgM or IgG or both

+Significantly

TABLE IV Comparison of results of culture for $C$ trachomatis and $\mathrm{N}$ gonorrhoeae and of serological tests on 60 patients with acute salpingitis

\begin{tabular}{|c|c|c|c|c|c|c|}
\hline \multirow{2}{*}{$\begin{array}{l}\text { Culture } \\
\text { result }\end{array}$} & \multirow{2}{*}{$\begin{array}{l}\text { No of } \\
\text { patients } \neq\end{array}$} & \multicolumn{2}{|c|}{ MIF ${ }^{*}$ test result } & \multirow{2}{*}{$\begin{array}{l}\text { No of } \\
\text { patients§ }\end{array}$} & \multicolumn{2}{|c|}{ IHA† test result } \\
\hline & & + & - & & + & - \\
\hline $\begin{array}{l}+ \\
\bar{T} \text { Total }\end{array}$ & $\begin{array}{l}23 \\
37 \\
60\end{array}$ & $\begin{array}{l}21 \\
27 \\
48\end{array}$ & $\begin{array}{r}2 \\
10 \\
12\end{array}$ & $\begin{array}{r}4 \\
56 \\
60\end{array}$ & $\begin{array}{r}4 \\
7 \\
11\end{array}$ & $\begin{array}{r}0 \\
49 \\
49\end{array}$ \\
\hline
\end{tabular}

* IgG antibodies

+ Gonococcal pilar antibodies

\# Specimens (cervical) cultured for $C$ trachomatis

\$Specimens (urethral, cervical and rectal) cultured for $\mathbf{N}$ gonorrhoeae

\section{STATISTICAL ANALYSIS}

There was a correlation between the severity of the tubal changes and the results of the MIF tests $(P<0.005)$ and between the duration of pelvic pain before attendance and the results of serological tests $(P<0 \cdot 009)$.

Four (7\%) of the 60 patients had a significant rise in antibody titres to both $C$ trachomatis and $M$ hominis. The three patients with a significant rise in the titre of IHA gonococcal pilar antibodies had no evidence of a current infection with chlamydia or mycoplasmas.

\section{CONTROLS}

Antibodies to $C$ trachomatis, $M$ hominis and $N$ gonorrhoeae were demonstrated in $8 \%, 8 \%$, and $6 \%$ of the sera from the control group of pregnant women.

\section{Discussion}

The spectrum and relative importance of various aetiological agents of acute salpingitis are influenced by such factors as the relative proportion of cases of different severity and the proportion of venereal and iatrogenic cases (for example, tubal infections occurring after curettage, legal abortion, and insertion of an intrauterine contraceptive device). The proportions of patients with primary and repeated tubal infection may influence the outcome of microbiological studies, as may the mean time interval between the onset of symptoms and sampling.

In the present series there was about the same number of mild, moderately severe, and severe cases. Approximately $85 \%$ of the cases could be classified as venereal and $20 \%$ of the patients had had salpingitis before. As in all series of patients with acute salpingitis, the time between the onset of symptoms and attendance varied considerably (from one day to more than two weeks).

The aetiological pattern of acute salpingitis seems to show geographical differences. The percentage of cases associated with gonorrhoea in recent studies from the USA has been about twice that of similar studies from Europe. ${ }^{34681521}$ A change in the aetiological pattern with time has also been found in Lund, Sweden; in the middle 1960s about every second case of acute salpingitis had gonorrhoea whereas 12 years later less than $10 \%$ of all cases were infected with gonococci. ${ }^{10}$

The time interval between collection of the first and second serum specimen from some patients was comparatively short-less than one week. In others, the time between exposure to infection and sampling of sera was fairly long (more than several months in some cases). This, of course, limits the possibility of demonstrating evidence of a current infection by a significant change in titre. With regard to $C$ trachomatis, however, a correlation was found between a positive serological test result, as well as the antibody titre at initial examination, and the duration of the disease before attendance.

Recently developed tests 19202223 for detecting gonococcal pilar antibodies have proved to be both sensitive and specific. Such antibodies may persist for years in patients treated for gonorrhoea. ${ }^{20} 22$ In the present series, gonorrhoea had been diagnosed earlier in only two patients, and gonococci could be recovered from only four of the 60 patients. Static, 
low titres of IHA gonococcal pilar antibodies and negative culture results were found in six patients, suggesting an antibody response to a past rather than to a present gonococcal infection.

Recent experimental studies ${ }^{24}$ in grivet monkeys indicate that chlamydia, like gonococci, can spread canalicularly to the Fallopian tubes and produce inflammatory changes that are similar to those found in women with gonococcal salpingitis. ${ }^{25}$ In such experimental studies $M$ hominis can spread to the parametria and produce parametritis and salpingitis. ${ }^{26}$

In the present series of patients $40 \%$ had IHA antibodies to $M$ hominis, while a significant rise in titre occurred in $12 \%$. Cultures of $M$ hominis were not regularly performed, but the serological test results suggest that current mycoplasmal infections had occurred in an appreciable number of the patients studied.

Of the three agents studied, antibodies occurred most often to $C$ trachomatis (80\%); $37 \%$ of patients had a significant rise in titre.

In experimental genital infection with $C$ trachomatis in grivet monkeys, IgM antibodies to the organism were detectable between one and two weeks after the infection and had disappeared after a further five or six weeks. ${ }^{27}$ Our experience so far suggests that even in deep-sited genital chlamydial infections in man, serum antibodies to the organism may persist for a limited period, provided adequate antibiotic therapy has been given. For example, patients with salpingitis with high titres of IgM and IgG antibodies to $C$ trachomatis, and from whom the organism was recovered from the cervix and the Fallopian tubes (and who were treated with tetracycline), had no detectable antibodies two years later. ${ }^{27}$ These findings might suggest that the vast majority of our patients in whom antibodies to $C$ trachomatis were detected had a current or comparatively recent chlamydial infection.

Chlamydia were isolated more often in those patients with no detectable antibodies and in those with a low (32-64) rather than a high (>128) IgG antibody titre. No chlamydia were cultured from the patients with IgM antibodies to $C$ trachomatis. These results indicate that an immune response to $C$ trachomatis may result in negative culture results for the organism in cervical specimens. Antibodies in cervical secretions may also have a similar effect.

In the population studied, the serological "background noise" was low; antibodies to $C$ trachomatis, $M$ hominis, and $N$ gonorrhoeae occurred in $<8 \%$ of the 50 pregnant women tested as controls, who were all inhabitants of Lund. However, in an earlier study of sera from women living in Landskrona in the same county (Skåne), chlamydial antibodies occurred in the cord blood of $25 \%$ of the infants of 139 puerperal women. ${ }^{28}$ In a recent study of 300 consecutive gynaecological patients treated in the same department as the patients with salpingitis $C$ trachomatis, $M$ hominis, and $N$ gonorrhoeae were isolated from the cervix of $6 \cdot 1 \%, 23 \%$, and $2 \cdot 3 \%$ respectively (unpublished data).

In the present study serological tests suggested a concomitant current infection with both chlamydia and mycoplasmas in $7 \%$ of the 60 patients. None of the few patients with gonorrhoea had evidence of a current infection with either chlamydia or mycoplasmas. In the 300 outpatients referred to above, chlamydia occurred in $13 \%$ of the $23 \%$ who harboured mycoplasmas and in $29 \%$ of those with gonorrhoea. $M$ hominis was recovered from $59 \%$ of those infected with $N$ gonorrhoeae.

This study showed that acute salpingitis in Lund is associated with a current genital chlamydial infection in at least $40 \%$ of patients, whereas gonococcal infections at present occur in only a small percentage $(8 \%)$ of all cases of salpingitis. Acute infections with $M$ hominis could be detected in $10-15 \%$ of the patients with acute salpingitis in the area.

To obtain optimum conditions for establishing the diagnosis of chlamydial and gonococcal salpingitis, our study indicates that cultures as well as serological tests should be performed.

This study was supported by a grant from the World Health Organisation, by grant $16 \mathrm{X}-4509$ from the Swedish Medical Research Council, and by grant 512-8215 from the Danish Medical Research Council.

\section{References}

1. Cunningham FG. The etiology and pathogenesis of pelvic inflammatory disease. Sex Transm Dis 1979;6:221-3.

2. Eschenbach DA, Holmes KK. The etiology of acute pelvic inflammatory disease. Sex Transm Dis 1979;6:224-7.

3. Chow AW, Malkasina KL, Marshall JR, Buze LB. Value of cul-de-sac cultures and relative importance of gonococci and other aerobic or anaerobic bacteria. Am J Obstet Gynecol 1975; 122: 876-9.

4. Cunningham FG, Hauth JC, Gilstrap LC, Herbert WNP, Kappus SS. The bacterial pathogenesis of acute pelvic inflammatory disease. Obstet Gynecol 1978;52:161-4.

5. Monif BRG, Welkos SL, Baer H, Thompson RJ. Cul-de-sac isolates from patients with endometritis-salpingitis-peritonitis and gonococcal endometritis. Am J Obstet Gynecol 1976; 126: 158-61.

6. Eschenbach DA, Buchanan TM, Pollock HM, et al. Polymicrobial etiology of acute pelvic inflammatory disease. $N$ Engl J Med 1975; 293: 166-71.

7. Mardh P-A, Weström L, Möller BR, Ripa KT. Pelvic inflammatory disease. II .Clinical, aetiological and pathophysiological studies. World Health Organization Working Documen INT/VDT 78.347. Geneva: WHO, 1978.

8. Treharne JD, Ripa KT, Mårdh P-A, Svensson L, Weström L, Darougar S. Antibodies to Chlamydia trachomatis in acute salpingitis. Br J Vener Dis 1979; 55:26-9.

9. Schulz W. Die Entzündungen der weiblichen Anhänge. Dtsch Med Wochenschr 1962;87:1568-72. 
10. Weström L, Mårdh P-A. Epidemiology, etiology and prognosis of acute salpingitis: a study of 1457 laparoscopically verified cases. In: Hobson D, Holmes KK, eds. Nongonococcal Urethritis and Related Infections. Washington DC: American Society for Microbiology, 1977: 84-90.

11. Mårdh P-A, Ripa TK, Svensson L, Weström L. Chlamydia trachomatis infections in patients with acute salpingitis. NEngl J Med 1977; 296: 1377-9.

12. Mårdh P-A, Ripa TK, Wang S-P, Weström L. Chlamydia trachomatis as an etiological agent in acute salpingitis. In: Hobson D, Holmes KK, eds. Nongonococcal Urethritis and Related Infections. Washington DC: American Society for Microbiology, 1977:77-83.

13. Mфller BR, Weström L, Ahrons $\mathrm{S}$, et al. Chlamydia trachomatis infection of the Fallopian tubes. Histological findings in two patients. Br J Vener Dis 1979;56:422-8.

14. Mårdh P-A, Weström L. Antibodies to Mycoplasma hominis in patients with genital infections and in healthy controls. $B r J$ Vener Dis 1970;46:390-7.

15. Mårdh P-A, Weström L. Tubal and cervical cultures in acute salpingitis with special reference to Mycoplasma hominis and T-strain mycoplasmas. Br J Vener Dis 1970;46:179-85.

16. Jacobson L, Weström L. Objectivized diagnosis of acute pelvic inflammatory disease: diagnostic and prognostic value of routine laparoscopy. Am J Obstet Gynecol 1969; 105: 1088-98.

17. Treharne JD, Darougar S, Jones BR. Modification of the microimmunofluorescence test to provide a routine serodiagnostic test for chlamydial infection. J Clin Pathol 1977; 30:510-7.

18. Krogsgaard-Jensen $A$. Indirect haemagglutination with mycoplasma antigens: Effects of $\mathrm{pH}$ on antigen sensitization of tanned fresh and formalinized sheep erythrocytes. Appl Microbiol 1971;22:756-9.

19. Reimann K, Lind I. An indirect haemagglutination test for demonstration of gonococcal antibodies using gonococcal pili as antigen. I Methodology and preliminary results. Acta Pathol Microbiol Scand (C) 1977;85: 115-22.

20. Reimann, K, Lind I, Andersen KE. An indirect haemagglutination test for demonstration of gonococcal antibodies using gonococcal pili as antigen. II Serological investigation of patients attending a dermatovenerological outpatients clinic in Copenhagen. Acta Pathol Microbiol Scand (C) 1980;88: 155-62.
21. Sweet RL, Mills J, Hadley KW, et al. Use of laparoscopy to determine the microbiologic etiology of acute salpingitis. Am J Obstet Gynecol 1979; 134:68-74.

22. Holmes KK, Buchanan TM, Adams JL, Eschenbach DA. Is serology useful in gonorrhea? A critical analysis of factors influencing serodiagnosis. In: Brooks GF, Gotschlich EC Holmes KK, Sawyer WD, Young FE, eds. Immunobiology of Neisseria gonorrhoeae. Washington DC: American Society for Microbiology, 1978;370-6.

23. Mårdh P-A, Buchanan T, Christensen P, Danielsson D, Lind I, Reimann K. Comparison of four serological tests for detection of gonococcal antibodies in patients with complicated gonococcal infections. In: Brooks GF, Gotschlich EC, Holmes KK, Sawyer WD, Young FE, eds. Immunobiology of Neisseria gonorrhoeae. Washington DC; American Society for Microbiology, 1978:377-81.

24 Møller BR Mårdh P-A. Experimental salpingitis in grivet monkeys by Chlamydia trachomatis. Modes of spread of infection to the Fallopian tubes. Acta Pathol Microbiol Scand (B) 1980;88: 107-14.

25. Curtis $\mathbf{A H}$. Bacteriology and pathology of fallopian tubes removed at operation. Surg Gynecol Obstet 1921;33:621-31.

26. Møller BR, Freundt EA, Black FT, Frederiksen P. Experimental infection of the genital tract of female grivet monkeys by Mycoplasma hominis. Infect Immunol 1978; 20:248-57.

27. Ripa KT, Møller BR, Mårdh P-A, Freundt EA, Melsen F. Experimental acute salpingitis in grivet monkeys provoked by Chlamydia trachomatis. Acta Pathol Microbiol Scand (B) 1979;87:65-70.

28. Mårdh P-A, Helin I, Bobeck S, Laurin J, Nilsson I Colonisation of pregnant and puerperal women and newborns with Chlamydia trachomatis. Br J Vener Dis 1980;56:90-100. 